\title{
BMJ Global Health Cost and cost drivers associated with setting-up a prime vendor system to complement the national medicines supply chain in Tanzania
}

\author{
August Kuwawenaruwa (D) ,1,2,3 Kaspar Wyss, ${ }^{2,3}$ Karin Wiedenmayer, ${ }^{2,3,4}$ \\ Fabrizio Tediosi (1) ${ }^{2,3}$
}

To cite: Kuwawenaruwa $A$, Wyss K, Wiedenmayer K, et al. Cost and cost drivers associated with setting-up a prime vendor system to complement the national medicines supply chain in Tanzania. BMJ Global Health 2020;5:e002681. doi:10.1136/ bmjgh-2020-002681

Handling editor Seye Abimbola

- Additional material is published online only. To view, please visit the journal online (http://dx.doi.org/10.1136/ bmjgh-2020-002681).

Received 20 April 2020 Revised 24 June 2020 Accepted 15 July 2020

(D) Check for updates

(C) Author(s) (or their employer(s)) 2020. Re-use permitted under CC BY-NC. No commercial re-use. See rights and permissions. Published by BMJ.

${ }^{1}$ Ifakara Health Institute, Dar es Salaam, United Republic of Tanzania

2University of Basel, Basel, Switzerland

${ }^{3}$ Swiss Tropical and Public Health Institute (Swiss TPH), Basel, Switzerland

${ }^{4}$ Health Promotion and System Strengthening (HPSS) project, Dodoma, United Republic of Tanzania

\section{Correspondence to} August Kuwawenaruwa; ajoachim@ihi.or.tz

\section{ABSTRACT}

Introduction Economic analysis of supply chain management interventions to improve the availability of healthcare commodities at healthcare facilities is important in generating evidence for decision-makers. The current study assesses the cost and cost drivers for setting-up a public-private partnership programme in Tanzania in which all public healthcare facility orders for complementary medicines are pooled at the district level, and then purchased from one contracted supplier, the prime vendor (referred to as 'Jazia Prime Vendor System' (Jazia PVS)). Methods Financial and economic costs of Jazia PVS were collected retrospectively and using the ingredients approach. The financial costs were spread over the implementation period of January 2014-July 2019. In addition, we estimated the financial rollout costs of Jazia PVS to the other 23 regions in the country over 2 years (2018-2019). A multivariate sensitivity analysis was conducted on the estimates.

Results Jazia PVS start-up and recurrent financial costs amounted to US\$2 170989.74 and US\$709302.32, respectively. The main cost drivers were costs for shortterm experts, training of staff and healthcare workers and the Jazia PVS technical and board management activities. The start-up financial cost per facility was US\$2819.47 and cost per capita was US\$0.37.

Conclusion In conclusion, the study provides useful information on the cost and cost drivers for setting-up a complementary pharmaceutical supply system to complement an existing system in low-income settings. Despite the substantial costs incurred in the initial investment and operations of the Jazia PVS, the new framework is effective in achieving the desired purpose of improving availability of healthcare commodities.

\section{INTRODUCTION}

Access to essential medicines of good quality, affordable, at the right time and place is essential for the attainment of universal health coverage. ${ }^{1}$ Access to medicines has been on the global agenda towards Sustainable Development Goal(s) in goal number three, specifically target eight. ${ }^{23}$ Achieving this target relies

\section{Key questions}

What is already known?

- Public-private partnerships in healthcare supply chains have the potential to improve service delivery; however, little is known on the start-up and recurrent costs of interventions that involve private partners to strengthen a healthcare supply system.

\section{What are the new findings?}

- The start-up costs were higher than recurrent costs, indicating the need for front loading substantial amount of resources.

- Short-term experts and training of staff and health workers comprised the largest component of startup costs.

- The largest share of the recurrent financial costs was for the payment of the Jazia Prime Vendor System (Jazia PVS) technical and board management activities and this corresponds to $80 \%$ of recurrent costs.

- Start-up financial costs per facility and per capita amounted to US\$2819.47 and US\$0.37, respectively, while recurrent financial costs amounted to US\$921.17 per facility and US\$0.12 per capita.

What do the new findings imply?

- The costs of external support to set-up an intervention to increase the availability of medicines is high.

- Integration of a health supply chain intervention into the existing regional and district administrative structures can contain implementation costs.

- Governments aiming at fostering improvements of health supply chains could consider building up public-private partnerships.

- Financial cost per facility and per capita is limited for start-up and recurrent operations once implemented, indicating that investment in a complementary prime vendor system supporting national supply seems appropriate and is effective in improving availability of healthcare commodities in the health facilities.

on the complex interactions between various actors in the pharmaceutical supply chain such as manufacturers, central medical stores, sector 
ministries, distributors (retailers and wholesalers), vendors, healthcare providers and the community. ${ }^{45}$

There has been an increase in the number of health system interventions to improve service delivery, targeting either supply or demand side or both. ${ }^{6-11}$ A recent systematic review conducted to assess whether in-country changes in the pharmaceutical supply chain models yield cost savings and improve the availability of health commodities found that both centralised tendering and procurement bring cost savings and improve efficiency. ${ }^{12}$ In addition, supply chain management interventions have been effective in reducing health commodities stock-outs and improve the availability of medicines for the population. ${ }^{12}{ }^{13}$ For example, in Thailand, the transition from the conventional vaccine supply and logistics systems to the vendor managed inventory resulted in a reduction of the cost of immunisation due to the reduction of vaccine wastage. ${ }^{14}$ Reduction of vaccine wastage resulted in a lower number of doses procured and the vendor system led to the elimination of vaccine storage at intermediate warehouses. Furthermore, information technology was improved alongside the vendor system, hence reducing the number of supply chain operators (regional and provincial levels) distributing directly to the hospitals, health centres or immunisation clinics. ${ }^{14}$ Likewise, in Jordan, a joint procurement bidding process for medical commodities achieved 5.2\%-17.0\% cost savings on drugs procured from the vendors. ${ }^{15}$ Other studies have found that medicines procurement through a formal tendering process reduces prices of the commodities and results in cost savings when compared with drugs purchased in the free market. ${ }^{16} 17$ Pharmaceutical procurement arrangements operating under framework agreements have been shown to significantly reduce the cost of the procurement process and shorten lead times. ${ }^{18}$ Economic analysis of a health system intervention is important for informing policy-makers of the resources required in implementing and scaling up such interventions into different settings, taking into consideration economies of scale. ${ }^{19} 20$

The United Republic of Tanzania piloted a supply chain intervention in three regions namely Dodoma, Morogoro and Shinyanga to complement the existing national pharmaceutical supply chain from 2014 to July 2019. The complementary procurement system in the regions has been successful in improving the availability of medicines at public healthcare facilities. ${ }^{21-24}$ Hence, the government decided to implement the Jazia Prime Vendor System (Jazia PVS) to all the 26 regions in 2018. ${ }^{21}$ The current study assesses the cost and cost drivers for setting-up Jazia PVS in public healthcare facilities within the pilot regions in Tanzania. In addition, we also estimated the financial costs for the Jazia PVS rollout to the remaining 23 regions in Tanzania. Economic analysis of interventions for improving the availability of essential medicines at the periphery is important to generate evidence for decision-makers when allocating limited resources. In addition, knowledge of the amount of resources needed for planning purposes and for informing decision-makers is critical when implementing effective and efficient complementary supply chains such as the Jazia PVS to improve public welfare.

\section{The Jazia Prime Vendor System}

In Tanzania, the Medical Store Department (MSD) is an independent department under the Ministry of Health, Community Development, Elderly and Children that is responsible for the supply of healthcare commodities to the public healthcare facilities and some of the faithbased organisation hospitals that serve as District Designated Hospitals. MSD delivers consignments directly to the respective facility based on a quarterly facility quantification of health commodity needs. However, a number of challenges hinder MSD efficiency, leading to low order fulfilment rates for supplies by MSD, such as inaccurate forecasting of pharmaceutical needs at facility levels, ineffective systems for fulfilling back-ordered items and weak supply chain. ${ }^{25}$ Healthcare facilities have resources earmarked for purchasing healthcare commodities from private pharmaceutical suppliers when MSD is out-ofstock. ${ }^{24}$ Initially, procurement from private pharmaceutical suppliers was reported to be poorly managed. ${ }^{24} \mathrm{~A}$ survey conducted in 2012 revealed that order fulfilment rate from the MSD was about $60 \%,{ }^{26}$ but facilities with resources could procure complementary supplies from private pharmacies. However, procurement was done from multiple private sources within and outside their district and region; incurring high opportunity costs (travel and fuel, per diems, high prices of medicines they purchase) in the process. The procedure was reported to be poorly managed. ${ }^{24}$

In 2014, the United Republic of Tanzania began implementing the Jazia PVS to supplement the MSD. The Jazia PVS is a unique public-private partnership (PPP) programme in which all the public healthcare facility orders for missing medicines at the MSD are pooled at the district level, and then purchased from one contracted prime vendor per region. The set-up of the Jazia PVS was funded by the Swiss Agency for Development and Cooperation and implemented by the Health Promotion and System Strengthening (HPSS) project. Both international and local experts were responsible for conceptualising, supporting and providing technical expertise. HPSS project staff supported the operations of the Jazia PVS in collaboration with government officers.

Jazia PVS was implemented alongside several activities, including capacity-building to healthcare staff, inventory and financial audits conducted at the facilities, monitoring and evaluation and peer cascade coaching. To ensure the sustainability of the system, Jazia PVS was anchored within the government structures and overseen by the regional administrative secretary, regional health management teams and council health management teams.

The Jazia PVS intervention pilot phase started in Dodoma region in 2014 and was later extended to 
Table 1 Regional information

\begin{tabular}{|c|c|c|c|}
\hline Variable & Dodoma & Morogoro & Shinyanga \\
\hline Population* & 2083588 & 2218492 & 1534808 \\
\hline Population growth rates & 2.1 & 2.4 & 2.1 \\
\hline Area coverage in square kilometres & 41311 & 70624 & 50781 \\
\hline Hospitals $†$ & 5 & 6 & 6 \\
\hline Number of public health centrest & 29 & 32 & 22 \\
\hline Number of public dispensaries $†$ & 251 & 233 & 186 \\
\hline Number of private health facilities $†$ & 62 & 128 & 55 \\
\hline Number of primary care facilities $\ddagger$ & 1.7 & 1.8 & 1.4 \\
\hline Assistant medical officers $\ddagger$ & 0.37 & 0.64 & 0.26 \\
\hline Medical doctors $\ddagger$ & 0.52 & 0.4 & 0.11 \\
\hline Assistant medical officers and medical doctorł & 0.89 & 1.04 & 0.37 \\
\hline Nurses/Midwives $\ddagger$ & 4.57 & 5.13 & 3.82 \\
\hline Pharmacy staff & 0.28 & 0.19 & 0.15 \\
\hline Laboratory staff & 0.27 & 0.45 & 0.19 \\
\hline Total staffing per facility & 6.9 & 7.85 & 4.9 \\
\hline
\end{tabular}

*National Bureau of Statistics, Tanzania National Bureau of Statistics; Population and Housing Census 2013.

thttp://hfrportal.ehealth.go.tz/ (accessed on 15 Jan 2018).

‡Per 10000 population 2013/14.

Morogoro and Shinyanga regions in 2016. After the government decided to integrate the successful pilot into national policy, the Jazia PVS was rolled-out and implemented in all regions of mainland Tanzania in 2019. Of the three pilot regions, the Morogoro region has the highest population, 2218492 followed by Dodoma with 2083588 and Shinyanga 1534808 (table 1). A total of 770 public facilities are covered by Jazia PVS, including 17 hospitals, 83 health centres and 670 dispensaries (table 1). Morogoro region has the largest number of public dispensaries (251) while Shinyanga has the least number of dispensaries (186). The number of primary care facilities per 10000 population is $1.7,1.8$ and 1.4 for Dodoma, Morogoro and Shinyanga, respectively (table 1).

Jazia PVS had a number of performance targets which were set out during its establishment. ${ }^{27}$ Online supplemental appendix table 2 presents Jazia PVS monitoring and evaluation performance results from 2015 to 2019 in terms of the availability of essential medicines in the pilot regions, with Dodoma reaching above 90\%, Shinyanga $87 \%$ and Morogoro $78 \%$. In addition, medicines, medical equipments and medical supplies worth US $\$ 9$ 172726.21 have been procured from the prime vendor during the pilot phase. Other performance indicators showed that satisfaction with the prime vendor was good; medicines order fulfilment rates were high and medicines were delivered within $4-15$ days. ${ }^{21}$

\section{METHODS}

\section{Costing approach}

Cost analyses can be implemented adopting a 'bottom-up' (microcosting or ingredients approach), a 'top-down' (macrocosting or activity-based) approach or a combination of the two approaches. ${ }^{28-30}$ Ingredients approach disaggregates the costs of a given output, linking them to specific items being assessed within the intervention. It measures quantities of resources used at the activity level. $^{28}$ Bottom-up costing comprehensively captures information on the resources used, and whether the data required for conducting analysis is available and easier to access. ${ }^{29}{ }^{31}$ In contrast, a 'top-down' approach divides intervention expenditures by a given number of outputs in order to calculate a unit cost. ${ }^{30} \mathrm{~A}$ top-down analysis of the economic costs, on the other hand, takes consideration of all the expenditure items at the central level and allocates the costs using formulae based on a number of factors such as office space usage in a building, number of staff and staff time spent on various activities. ${ }^{29} 32$ Economic costing using any of the approaches above can be captured retrospectively, prospectively or using both. ${ }^{30} 33$ The prospective approach allows analysts to directly observe resource use and avoids/minimises recall bias. Nevertheless, the use of such approach may influence resource use in the implementation process of intervention. ${ }^{30}{ }^{34}$ In this study, the cost assessment of Jazia PVS was conducted when it was already implemented in the three pilot regions and as such, implementation costs were collected retrospectively. The retrospective approach is reliable and usually works well if relevant financial and implementation reports are available to 
track resources used. ${ }^{30}$ The current study has adopted an ingredients approach.

We considered public healthcare facilities as Jazia PVS caters for public healthcare facilities only, with no private healthcare facilities participating in the programme. Data collection was conducted between July and September 2018 based on the range of activities performed in the implementation of the Jazia PVS (online supplemental appendix table 3). Using the ingredients approach, we captured information on the quantities of time and other resources, together with their unit cost (online supplemental appendix table 4). Unit costs were multiplied by the respective quantities of inputs used to obtain total cost ${ }^{193035}$ (online supplemental appendix table 5). A checklist for Consolidated Health Economic Evaluation Reporting Standards was completed to ensure that all recommended sections in reporting economic evaluation were covered (online supplemental appendix table 8).

\section{Data sources}

Several sources of information were used to estimate the costs to implement Jazia PVS. These included Jazia PVS financial reports and coordination office reports, government salary scales, HPSS planning meeting reports and semi-structured interviews (online supplemental appendix table 1). A total of 30 semi-structured in-depth interviews were conducted to capture information on resources used to implement Jazia PV, such as staff time. A costing survey tool was used to capture information for different activities undertaken with the Jazia PVS (online supplemental appendix table 3 ). In addition, we conducted a document review of the intervention design, implementation monitoring and evaluation reports, and of the HPSS financial reports. We extracted expenditure information on staff allowances, training, meetings, schedules for auditing as well as monitoring and evaluation activities. All information for the economic cost at the district and facility level were later on extrapolated to the regional level. We used the government salary scale based on the position of the staff and self-reported salary. This was also supplemented with salary information for health and non-health staff obtained from salary explorer website,$^{36}$ and health and medical average salaries in Tanzania 2018.

\section{Financial analysis}

Jazia PVS financial cost represents the real expenditure incurred ('paid for') ${ }^{30}$ in the process of conceptualisation and supporting the implementation of the intervention. ${ }^{30} 37$ Jazia PVS financial costs are grouped into start-up and recurrent costs. We estimated the Jazia PVS financial start-up costs from January to December 2014 for Dodoma and January to December 2016 for Morogoro and Shinyanga regions. Jazia PVS start-up costs included all the expenses incurred between the conceptualisation of the idea and actual operation (the time when healthcare facilities and districts started procuring and receiving medicines from the prime vendor). Some of the start-up costs included payment to short-term pharmaceutical experts, baseline healthcare facility assessment, advocacy and orientation to stakeholders, suppliers/vendors prequalification and tendering for short-listed/prequalified vendors, the official launch of the Jazia PVS in the pilot regions, preparation of Jazia PVS official documents as well as training of trainers and health workers. At least one staff from each dispensary, two from each health centre and three from hospitals participated in the Jazia PVS training.

Financial costs were also incurred for the purchase of capital equipment such as computers, furniture, signposts, water dispensers and printing machines. These costs were included within the establishment of Jazia PVS office. We consider capital cost as any equipment with a lifespan of $>1$ year and its purchase price worth $>$ US $\$ 100$. Three computers were bought and installed at the regional coordinating offices in Dodoma, Morogoro and Shinyanga and were only used for Jazia PVS activities.

Recurrent financial costs comprised expenses incurred during the actual operation of the Jazia PVS from January 2015 to July 2019 for Dodoma and January 2018 to July 2019 for Morogoro and Shinyanga regions. Such costs included Jazia PVS regional coordinating office personnel allowances, monitoring and evaluation, medicine and financial audits at the facility level, Jazia PVS technical and board meeting management activities and allowances for various trainings and meetings. Each of the three regional Jazia PVS coordination offices operated with three staff: a senior staff/pharmacist, a pharmacy technician and one junior staff who were responsible for overseeing the Jazia PVS activities. These costs were captured up to 31 July 2019 at the closure of Jazia PVS pilot phase, and have also been spread over the Jazia PVS implementation period. In the financial analysis, we excluded the costs for experts based in Switzerland together with HPSS project overall costs and we only considered the direct costs for the implementation of Jazia PVS. Jazia PVS activities in Morogoro and Shinyanga were implemented concurrently. Separation of the financial costs for both regions was based on a share of the total public healthcare facilities in the region (56\% for Morogoro and 44\% for Shinyanga). We used the share of healthcare facilities for separation of costs as Jazia PVS was intended to improve availability of healthcare commodities at the facility level. At least one staff from each of the 271 facilities in Morogoro and at least one staff from each of the 214 facilities in Shinyanga participated in Jazia PVS capacity building.

\section{Economic analysis}

We estimated economic cost for the Jazia PVS start-up from January to December 2014 for Dodoma and January to December 2016 for Morogoro and Shinyanga regions. Jazia PVS initial implementation started in Dodoma 2014 where most of Jazia PVS start-up activities took place. Jazia PVS start-up cost has been considered as a capital investment and has been discounted and annualised over 
the life of the intervention. ${ }^{30} 38$ We estimated economic costs of staff and healthcare workers who reported participating in any of the Jazia PVS activities. The Jazia PVS coordination offices were located within the regional hospitals, therefore no costs were incurred for utilities and rent. However, for estimating the economic cost of the Jazia PVS office in the three pilot regions, we have used the market value per square metre inclusive of the utilities (US $\$ 17.5$ per square metre per month). Equipment supplied to the Jazia PVS offices were annualised using a discount rate of $3 \%$ and a useful life of 5 years, consistent with economic analysis guidelines where a minimum of $3 \%$ discount rate is recommended for international comparison purpose. ${ }^{30} 38$ Initial healthcare worker training followed a step-down approach and assumed to have a useful life of 3 years. We had no baseline assessment of the costs for the previous system of procuring complementary healthcare commodities from private supplies, therefore the comparator was 'do-nothing'.

\section{Financial costs for the national rollout of Jazia PVS}

We estimated the Jazia PVS financial rollout costs to the other 23 regions of Tanzania covering 112 hospitals, 464 health centres and 4318 dispensaries over 2 years (2018-2019). Jazia PVS scale-up costs are modelled based on the estimated cost from the pilot regions and costs are estimated based on a number of assumptions (online supplemental appendix table 6). Assumptions include: a prime vendor for a given region is contracted for 2 years and re-evaluated, a prime vendor continues to deliver consignments at the district level and facilities pick/retrieve their consignment at the district level, start-up activities include a baseline health facility assessment, advocacy and orientation of stakeholders, prequalification and tender for the prequalified vendors is performed once after every 3 years, an official event launches the Jazia PVS, training of trainers and health workers is conducted once and each region provides a Jazia PVS coordination office. For Jazia PVS recurrent activities, we assumed that each region constitutes a prime vendor technical commission and a tender board team which meets at least twice a year. In addition, Jazia PVS monitoring and evaluation together with inventory and financial audits at the facility level are conducted twice a year. Each facility is visited at least once during the contract duration of 2 years. We considered scale-up cost with 30\% technical support from national and international pharmaceutical consultants and without technical support. The assumption is that resources to finance and run the Jazia PVS are covered by respective regional authorities. Jazia PVS is assumed to be fully integrated into the government regional and district administrative structures, with some financial resources from the government required to support the training of health workers, monitoring and evaluation and establishment of regional coordination offices.

\section{Sensitivity analysis}

Cost estimates for interventions are surrounded by uncertainty arising from the unit cost used in the valuation of resources inputs; the efficacy of an intervention; choice of the discount rate and inflation rate and the need to extrapolate the results. ${ }^{3033}$ To account for uncertainty, varying individual input into the model 'one way' or varying two or more inputs at the same time (multivariate sensitivity analysis), while observing the changes in the outcomes is usually advised. ${ }^{30} 3339 \mathrm{We}$ performed a multivariate sensitivity analysis to account for varying useful life of capital items ( 3,5 and 10 years) and discount rate $(3 \%, 5 \%$ and $10 \%)$. The base year for analysis is 2018. Cost data are adjusted for inflation using the local currency, Tanzania Shillings (TZS) and the local inflation rates (Tanzania gross domestic product deflator) and subsequently converted to US $\$$ for international comparison. ${ }^{3040}$ Kumaranayake argues that the appropriate measure for adjusting costs should be the one that is closely related to the general price level of the resources used to implement the intervention. ${ }^{41}$ Results of the study are expressed in 2018 US $\$$, where the conversion rate was $2230 \mathrm{TZS}$ per US $\$ .{ }^{42}$

\section{Patient and public involvement}

Patients or the public were not involved in the design, conduct, reporting or dissemination plans of our research. The study findings will be shared with the regional and district healthcare managers of the different sites where the study was conducted and at policy level.

\section{RESULTS}

\section{The financial cost of the Jazia PVS intervention}

Table 2 presents the Jazia PVS start-up financial costs, where the total cost amounted to US\$2 170989.74 . Of the total start-up costs, $57.1 \%$ (US\$1 239868.87 ) was for the payment of the short-term international and national pharmaceutical experts, US $\$ 427683.15$ for Dodoma region and US\$454824.01 and US $\$ 357361.72$ for Morogoro and Shinyanga regions, respectively. When these costs are spread over the pilot phase, they amount to US\$76 645.73 for Dodoma and US\$127045.81 for Morogoro and US\$99821.71 for Shinyanga. Training of the staff and healthcare workers accounted for 27.9\% (US\$605 060.13). When these costs were spread over the pilot phase, they amounted to US\$49 042.47 per year in Dodoma and US $\$ 51839.60$ for Morogoro and US $\$ 40731.11$ for Shinyanga regions. The health facility baseline assessment and the official launch of the Jazia PVS amounted to US\$117406.86 and US\$79951.42 respectively. Further analysis showed that the cost per facility was US\$2819.47 (US\$2857.19 for Dodoma and US\$2854.29 for Morogoro and US\$2840 for Shinyanga regions). Cost per capita was US\$0.39 for Dodoma and US $\$ 0.35$ for Morogoro and US $\$ 0.40$ for Shinyanga (table 2). 


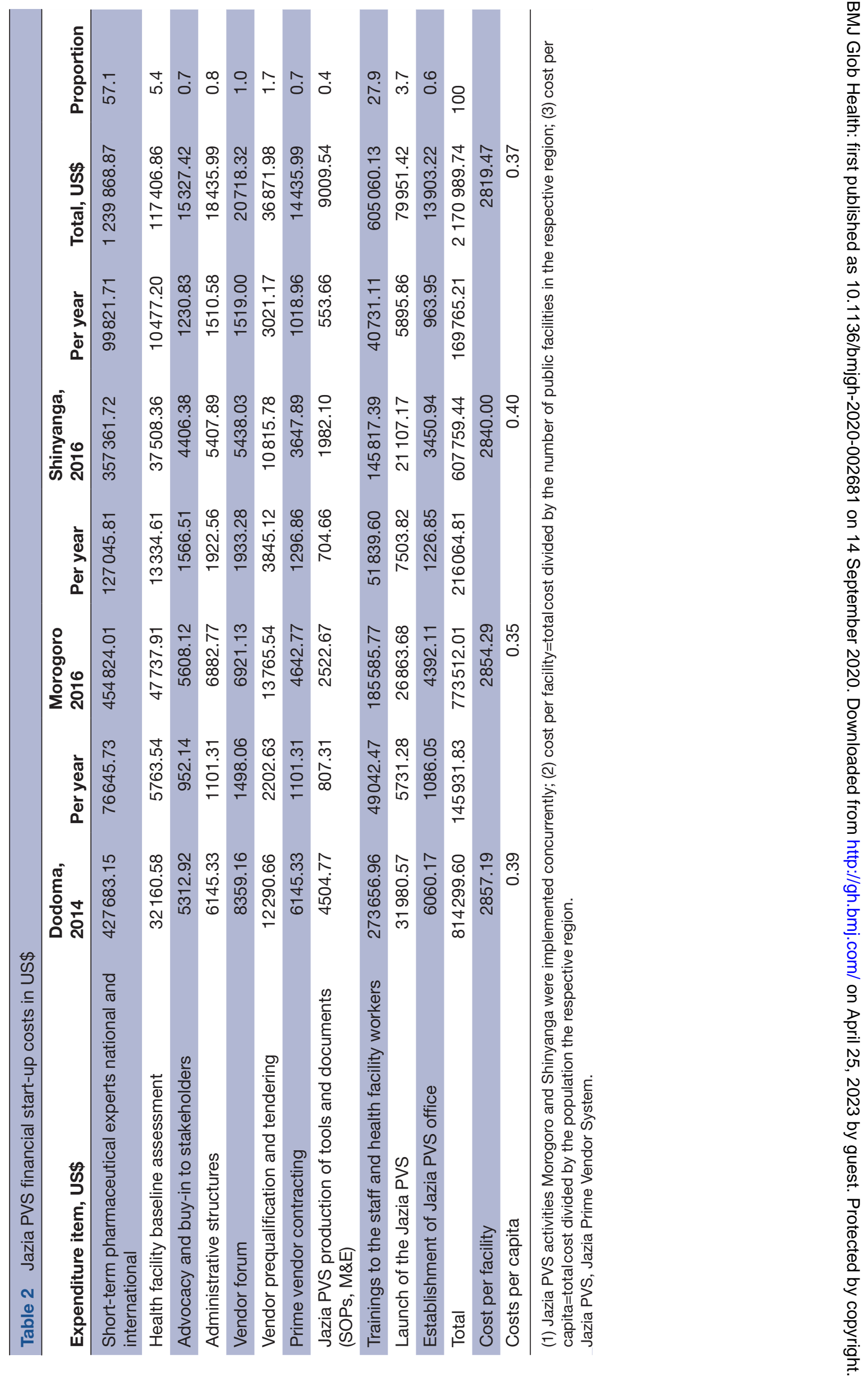


The total recurrent financial cost for Jazia PVS was US $\$ 709302.32$ (table 3). The largest share $(80.2 \%$ ) of the recurrent financial costs was used for the payment of the Jazia PVS technical and board management meetings and allowances. About 8.5\% (US\$60 485.50) was for the payment of allowances and operational costs for the Jazia regional coordination office while $6.3 \%$ (US $\$ 44$ 530.93) was for Jazia PVS-specific monitoring and evaluation activities. Cost per facility amounted to US $\$ 1114.57$ in Dodoma and US\$809.31 for Morogoro and US\$635.89 for Shinyanga. Recurrent cost per capita was US $\$ 0.15$ for Dodoma and US $\$ 0.10$ for Morogoro and US $\$ 0.08$ for Shinyanga (table 3).

\section{The economic cost of the Jazia PVS intervention}

Table 4 presents the economic costs of Jazia PVS start-up and recurrent costs in US\$. Results show that Jazia PVS start-up costs accounted for about 52.2\% (US\$1 209 573.47 ) of the total economic costs. Of the economic costs, $6.0 \%$ (US\$138 567.99) was for the official launch of the Jazia PVS, 6.3\% (US\$146 684.21) was for the healthcare facility baseline assessment and the largest share $32.0 \%$ (US $\$ 741836.55$ ) was for training of staff and healthcare workers (table 4).

Recurrent cost accounted for $47.8 \%$ (US\$1 106 440.94), whereas $27 \%$ (US $\$ 634$ 056.57) was for the technical and board management meetings and allowances, $7.0 \%$ (US $\$ 161$ 164.20) was for the ongoing Jazia PVS activities (including quantification, submission of documents at the district headquarter, inspection and picking-up consignment), 4.6\% (US\$106 644.94) for monitoring and evaluation activities, while $2.7 \%$ (US $\$ 61$ 694.07) was for inventory and financial audits conducted at the healthcare facilities (table 4).

Table 5 presents information on the Jazia PVS rollout costs to 23 more regions with and without technical assistance. Training of the staff and healthcare workers accounted for $45.8 \%$ (US\$3 618 682.96) of the costs, $8.5 \%$ (US\$670 487.78) for healthcare facility baseline assessment and $6.0 \%$ (US $\$ 471840.28$ ) for the official launch of the Jazia PVS for each region without technical assistance. Of the Jazia PVS recurrent costs, 9.0\% (US $\$ 712$ 589.74) was for the Jazia PVS regional coordination offices, $7.3 \%$ (US\$573 958.55) for monitoring and evaluation, while $4.5 \%$ (US\$352 757.90) was used for the inventory and financial audits without technical assistance (table 5). The national rollout cost per region amounts to US\$343815.93 ( US\$171907.97 per year).

\section{Sensitivity analysis}

The sensitivity analysis results show that the values are sensitive to the capital asset useful life and discount rate. When varying the capital assets' useful life and the discount rates, total economic start-up cost ranged between US $\$ 1441.71$ and US\$12667.06 (online supplemental appendix table 7).

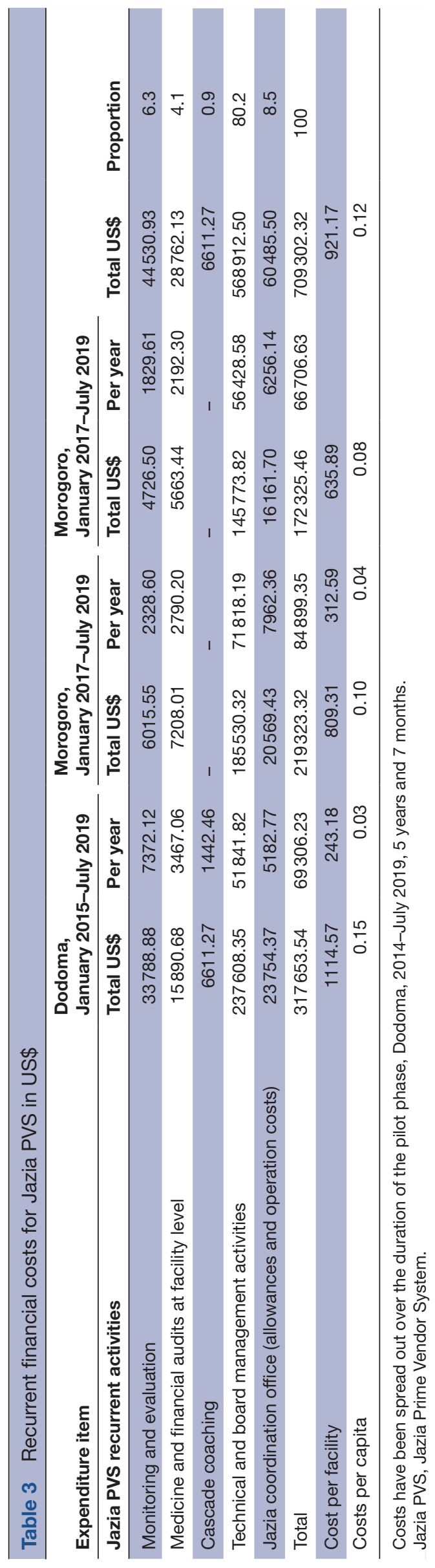




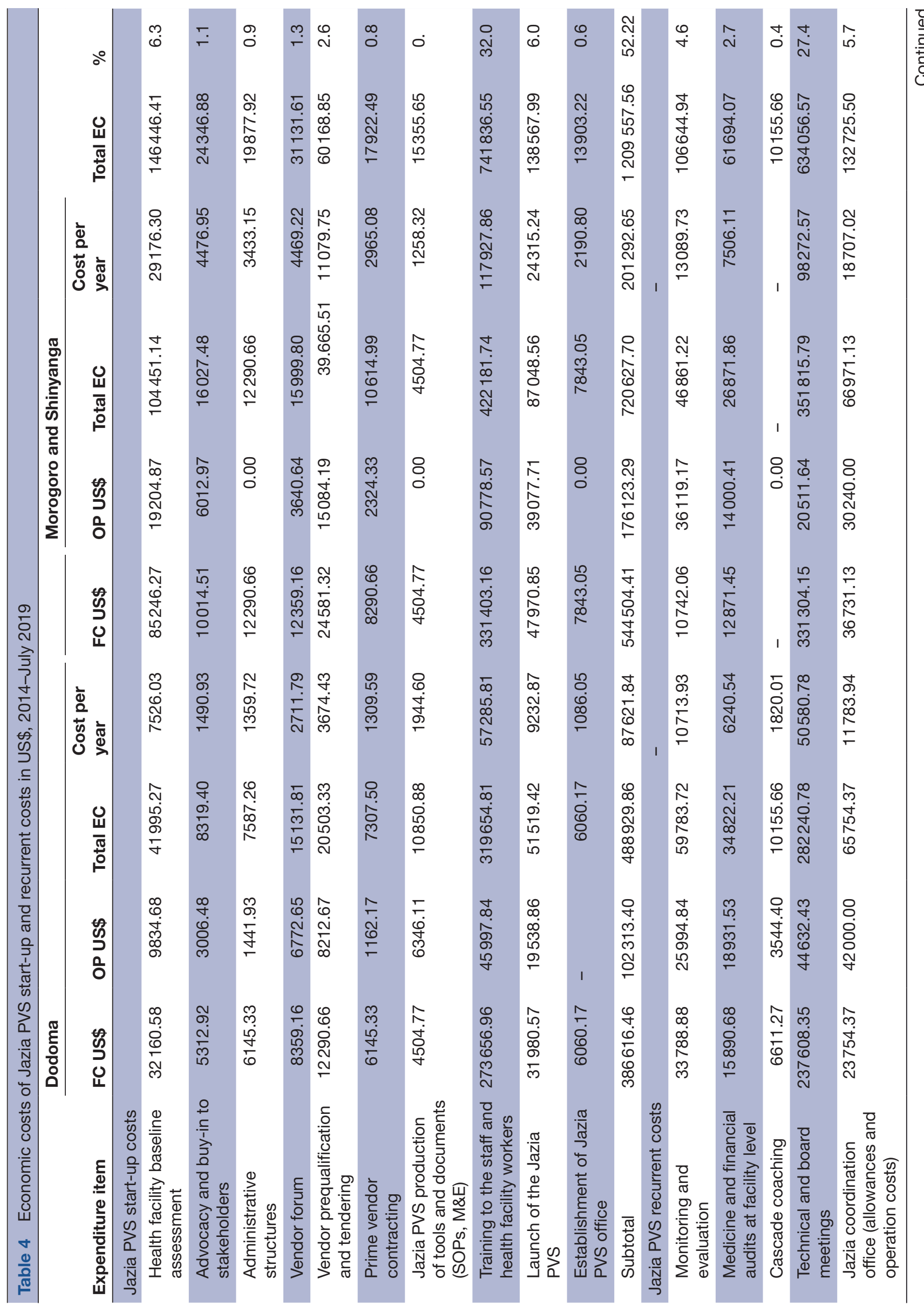




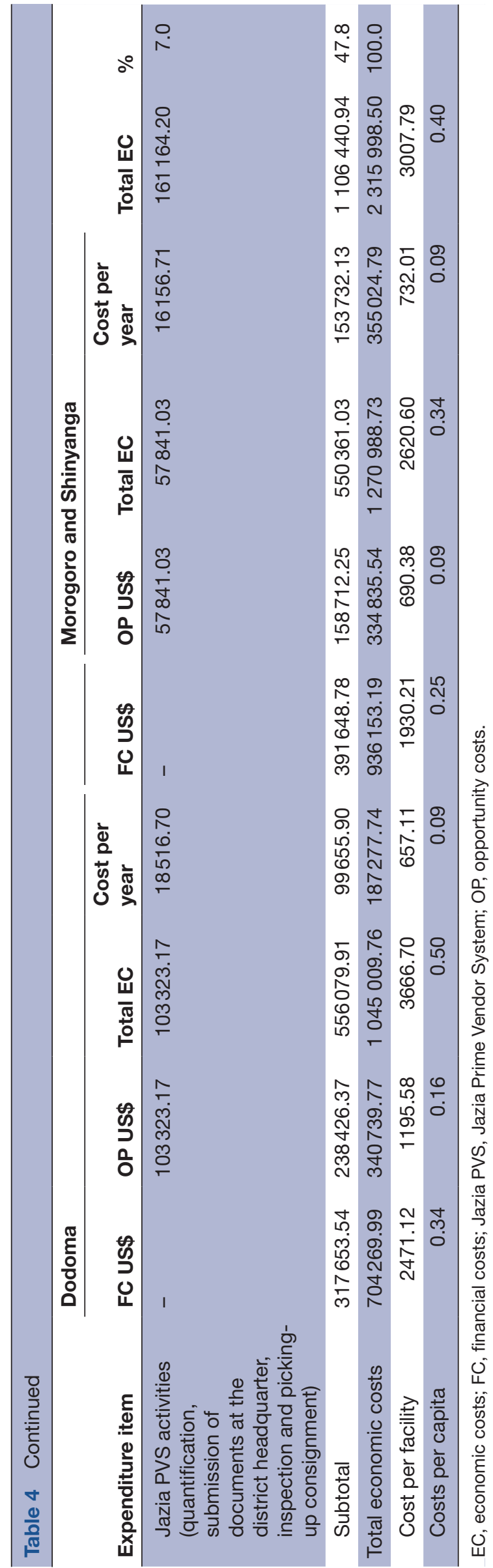

\section{DISCUSSION}

The study aimed to assess the cost and cost drivers for setting-up a complementary pharmaceutical supply system in public healthcare facilities in Tanzania to supplement the supply gap by the national MSD. We found that for the financial start-up costs, the largest share of the costs incurred was for the payment of shortterm pharmaceutical consultants both national and international and for training of the healthcare workers. The largest share of the Jazia PVS financial recurrent costs was for the Jazia PVS technical and board management activities. Similar trends were observed for the Jazia PVS economic costs, where the highest start-up costs were for the staff and healthcare workers training while Jazia PVS technical and board meetings accounted for the largest share of the recurrent economic costs. Jazia PVS rollout costs show that a high proportion of the costs were for the training of staff and health facility workers.

In this study, a significant share of the initial costs was for staff training, which is similar to a study conducted in Zambia to assess the cost-effectiveness of supply-chain interventions. The study found that training costs for the district personnel were higher compared with other costs such as staff recruitment, salaries and transport. ${ }^{9}$ Though costly, such training and mentorship programmes have been found to improve staff skills as well as the overall quality of service delivery. ${ }^{43}$ With the Jazia PVS, a stepdown cascading approach was used for training of staff at various levels, to control costs. This approach is validated by findings from a study conducted in Nigeria including training of staff involved in laboratory systems. They found that utilisation of training-of-trainers and stepdown training methods was a cost-effective system in the provision of the training to laboratory staff and allowed for a broader sharing of the training across laboratory staff. ${ }^{43}$ Equally important, staff training on supply chain management across cadres and levels helped maintain the sustainability of the intervention. Similar to this study, Goodman et al conducted an economic analysis of replicating training for drug retailers in Kenya to improve the management of malaria. ${ }^{44}$ They found that training of trainers and the drug retailers accounted for the largest share of the implementation costs, while community advocacy and monitoring and evaluation activities accounted for the smallest of the implementation costs. ${ }^{44}$ A study conducted in a different setting in Tanzania showed that staff training on the web-based electronic logistics management information system (eLMIS) intervention accounted for $>50 \%$ of the investment costs, however, there were enormous cost savings after upgrading the eLMIS. $^{45}$

The Jazia PVS received significant technical assistance from both in-country and external, from the conception of the idea to the completion of the pilot phase. Our findings are similar to a costing study conducted in Malawi, where they found that technical assistance accounted for the largest share of the costs, followed by the installation 
Table 5 Estimates for the Jazia PVS national rollout financial costs, 2018-2019

\begin{tabular}{|c|c|c|c|c|}
\hline Expenditure item & $\begin{array}{l}\text { No technical } \\
\text { assistance US\$ }\end{array}$ & Proportion & $\begin{array}{l}30 \% \text { technical } \\
\text { assistance US\$ }\end{array}$ & Proportion \\
\hline \multicolumn{5}{|l|}{ Jazia PVS start-up costs } \\
\hline Health facility baseline assessment & 670487.78 & 8.5 & 680965.00 & 8.5 \\
\hline Advocacy and buy-in to stakeholders & 89218.22 & 1.1 & 90612.36 & 1.1 \\
\hline Administrative structures & 106941.74 & 1.4 & 108612.84 & 1.4 \\
\hline Vendor forum & 122379.68 & 1.5 & 124292.01 & 1.5 \\
\hline Vendor prequalification and tendering & 213883.48 & 2.8 & 217225.69 & 2.8 \\
\hline Prime vendor contracting & 85756.56 & 1.1 & 87096.61 & 1.1 \\
\hline $\begin{array}{l}\text { Jazia PVS production of tools and documents (SOPs, } \\
\text { M\&E) }\end{array}$ & 54533.92 & 0.7 & 55386.09 & 0.7 \\
\hline Training to the staff and health facility workers & 3618682.96 & 45.8 & 3675229.46 & 45.8 \\
\hline Launch of the Jazia PVS & 471840.28 & 6.0 & 479213.38 & 6.0 \\
\hline Establishment of Jazia PVS office & 82806.02 & 1.0 & 84099.97 & 1.0 \\
\hline Subtotal & 5516530.65 & 69.8 & 5602733.42 & 69.8 \\
\hline \multicolumn{5}{|l|}{ Jazia PVS recurrent activities } \\
\hline Monitoring and evaluation & 573958.55 & 7.3 & 582927.38 & 7.3 \\
\hline Medicine and financial audits at facility level & 352757.90 & 4.5 & 358270.19 & 4.5 \\
\hline Cascade coaching & 270117.47 & 3.4 & 274338.40 & 3.4 \\
\hline Technical and board management activities & 481812.09 & 6.1 & 489341.01 & 6.1 \\
\hline $\begin{array}{l}\text { Jazia coordination office (allowances and operation } \\
\text { costs) }\end{array}$ & 712589.74 & 9.0 & 723724.86 & 9.0 \\
\hline Subtotal & 2391235.76 & 30.2 & 2428601.84 & 30.2 \\
\hline Total & 7907766.41 & 100.0 & 8031335.3 & 100.0 \\
\hline Cost per facility & 1615.81 & & 1641.06 & \\
\hline Costs per capita & 0.16 & & 0.16 & \\
\hline
\end{tabular}

Jazia PVS, Jazia Prime Vendor System.

of the software and training of the staff responsible for the supply chain. ${ }^{46}$

In Nepal, a new model for the distribution of vitamin A capsules to children of 6-60 months of age carried out by using female community health workers showed that community advocacy activity accounted for about $27.4 \%$ of the initial cost, while health worker's training and monitoring accounted for $12.7 \%$ and $9.6 \%$, respectively. ${ }^{47}$ Despite this investment in the advocacy and training activities, the new model for the distribution of vitamin A capsules was found to be highly cost-effective. ${ }^{47}$ A different programme conducted in the same country as a collaborative training programme between the government and private (retailers and wholesalers) suppliers of drugs showed that training cost accounted for about $39.1 \%$ of the financial cost. ${ }^{48}$

With regard to pooled procurement, Chaudhury et al assessed a policy intervention which aimed to improve the rational use of drugs in Delhi, India and found that a pooled procurement system offers added advantage in terms of quality drugs and reduction of the procurement cost and leads to the improved healthcare commodities' availability of $>80 \%$ at health facilities. However, financial or economic costs were not assessed and reported for the implementation of the programme. ${ }^{49}$

In this study, we found that the financial start-up and recurrent costs of pilot phase for the three regions amounted to US $\$ 2.8$ million, covering a population of $5836888^{50}$ (this is equivalent to US $\$ 0.49$ per capita). The rollout financial cost amounted to about US\$8 038 150.50 , covering a population of $37788466^{50}$ (US\$0.213 per capita). A recent statistic from the Bank of Tanzania shows that the gross domestic product per capita (current US\$) for the fiscal year 2018/2019 was US $\$ 1090 .{ }^{51}$ The costs of introducing the Jazia PVS are minimal compared with the country per capita income. Hence, the investment in a complementary supply chain system supporting national supply of health commodities and improving availability of medicines at the public healthcare facilities seems appropriate.

From the beginning, Jazia PVS was integrated into government structures. Similarly, Sorensen et al, ${ }^{52}$ argue that an intervention should be fully or partially integrated into the existing medicines supply chain structures, as in most cases creating a parallel supply chain tends to escalate overall management and operational costs. A study 
conducted in Kenya showed that integration of complementary commodity supply chains into a national supply chain resulted in $42 \%$ savings in overall recurrent costs and improved effectiveness of the supply chain..$^{53}$

Nonetheless, the study suffers from some limitations. We collected primary data from different levels of implementation retrospectively to estimate the economic costs, which have a potential limitation of recall bias. Participants tend to forget some of the initial activities if the recall period is more than a year. A mix of prospective and retrospective approaches could be of potential value in capturing all resources used from the start of the intervention. Furthermore, we did not have a baseline assessment on the costs incurred for the purchase of complementary pharmaceutical supplies in the pilot regions previous to the Jazia PVS introduction. This would have been of added value in conducting a costbenefit analysis of the Jazia PVS. Future studies could assess the cost-effectiveness of such complementary pharmaceutical supply chain. Finally, we could not find any published studies focusing on the costing and cost drivers of interventions targeting at complementary supply chain in low-income settings for comparison with our findings. Most studies assessed the whole supply chain system or components of the supply chain such as vertical (vaccination distribution) programmes. ${ }^{47}$ Therefore, the settings and design of available studies do not allow for meaningful comparison. Furthermore, the identified published studies were not related to a prime vendor system.

\section{CONCLUSION}

To our knowledge, this has been the first study exploring start-up and recurrent costs of an intervention in the pharmaceutical sector to complement and enhance a national supply system. Our findings show cost and cost drivers for setting-up a complementary pharmaceutical supply system for public healthcare facilities in a lowincome setting. The main cost drivers for the start-up of the Jazia PVS system were costs for short-term experts, training of staff and healthcare workers and the Jazia PVS technical and board management activities. The recurrent costs were lower compared with the start-up cost and the largest share of the recurrent financial costs was used for the payment of the Jazia PVS technical and board management activities. Despite the substantial costs incurred in the initial investment and operations of the Jazia PVS, the new framework for procurement of complementary medicines is effective in achieving the desired purpose of improving availability of essential medicines in the public healthcare facilities. The study provides useful financial information for other countries intending to adopt such an innovative PPP for improvement of the in-country pharmaceutical supply chain. The start-up costs were higher than recurrent costs, indicating the need for front loading a significant amount of resources. Policy adoption and anchoring in existing government structures rather than parallel systems resulted in decreased implementation and recurrent costs and ensured sustainability. Governments aiming at fostering efficiency and cost improvements of health supply chains could consider implementing integrated prime vendor systems.

Twitter Fabrizio Tediosi @fabrizio2570

Acknowledgements The authors would like to acknowledge the assistance of the Health Promotion and System Strengthening (HPSS) project in Dodoma, Tanzania. The authors would like to thank Patrick Hanlon (from the Swiss Centre for International Health $(\mathrm{SCIH})$ ) for his support and advice during data analysis. The authors would also like to thank regional and district managers together with the facility-in-charges at the sampled facilities for their support during the study.

Contributors AK and FT conceptualised the study. AK participated in data analysis interpretation of data and drafted the manuscript; KWi participated in interpretation and contextualisation of results. KWy and FT contributed to interpretation of results and in writing the manuscript. All authors have critically reviewed the manuscript and approved the final version.

Funding This manuscript is an output from the project: Health Systems Governance for an Inclusive and Sustainable Social Health Protection in Ghana and Tanzania funded by the Swiss Programme for Research on Global Issues for Development (r4d programme, phase I). The project involves a consortium of five partners: Swiss Tropical and Public Health Institute, ETH Zurich, University of Applied Sciences and Arts of Southern Switzerland (SUPSI), Ifakara Health Institute Tanzania and University of Ghana.

Competing interests None declared.

Patient and public involvement Patients and/or the public were not involved in the design, or conduct, or reporting, or dissemination plans of this research.

Patient consent for publication Not required.

Ethics approval The permission to conduct the study was obtained from the institutional review board (IH//RB/No. 21-2017), and the National Institute for Medical Research, ethics review board (NIMR/HQ/R.8a/Vol. IX/2720). Endorsement letters were obtained from the President's Office Regional Administration and Local Government offices (Ref No. AB.307/323/02/69), respective regional and districts health managers. All study participants were thoroughly informed about the study, and written consent was obtained from all study participants. Confidentiality of the participant's information was assured at all times, and data anonymity was considered during data collection and analysis.

Provenance and peer review Not commissioned; externally peer reviewed.

Data availability statement All data relevant to the study are included in the article or uploaded as supplementary information.

Open access This is an open access article distributed in accordance with the Creative Commons Attribution Non Commercial (CC BY-NC 4.0) license, which permits others to distribute, remix, adapt, build upon this work non-commercially, and license their derivative works on different terms, provided the original work is properly cited, appropriate credit is given, any changes made indicated, and the use is non-commercial. See: http://creativecommons.org/licenses/by-nc/4.0/.

\section{ORCID iDs}

August Kuwawenaruwa http://orcid.org/0000-0001-8459-443X

Fabrizio Tediosi http://orcid.org/0000-0001-8671-9400

\section{REFERENCES}

1 Rankin J, Quickand J, Muziki S. Operational principles for good pharmaceutical procurement, Geneva, Switzerland, 1999.

2 Beran D, Pedersen HB, Robertson J. Noncommunicable diseases, access to essential medicines and universal health coverage. Glob Health Action 2019;12:1670014.

3 UN. United nations General assembly transforming our world: the 2030 agenda for sustainable development. New York: United Nations, 2015.

4 Bhakoo V, Chan C. Collaborative implementation of e-business processes within the health-care supply chain: the Monash pharmacy project. Supp Chain Mnagmnt 2011;16:184-93. 
5 Chung SH, Kwon C. Integrated supply chain management for perishable products: dynamics and oligopolistic competition perspectives with application to pharmaceuticals. Int J Prod Econ 2016;179:117-29.

6 Senkubuge F, Modisenyane M, Bishaw T. Strengthening health systems by health sector reforms. Glob Health Action 2014;7:23568.

7 Jannati A, Sadeghi V, Imani A, et al. Effective coverage as a new approach to health system performance assessment: a scoping review. BMC Health Serv Res 2018;18:886.

8 Garchitorena A, Miller AC, Cordier LF, et al. Early changes in intervention coverage and mortality rates following the implementation of an integrated health system intervention in Madagascar. BMJ Glob Health 2018;3:e000762.

9 Vledder M, Friedman J, Sjöblom M, et al. Improving supply chain for essential drugs in low-income countries: results from a large scale randomized experiment in Zambia. Health Syst Reform 2019;5:158-77.

10 Sylim P, Liu F, Marcelo A, et al. Blockchain technology for detecting Falsified and substandard drugs in distribution: pharmaceutical supply chain intervention. JMIR Res Protoc 2018;7:e10163.

11 Kokilam MB, Joshi HG, Kamath VG. Strengthening the pharmaceutical supply chain management with information communication technology intervention: a Windfall to the Indian rural public healthcare system. J Health Manag 2016;18:274-89.

12 Seidman G, Atun R. Do changes to supply chains and procurement processes yield cost savings and improve availability of pharmaceuticals, vaccines or health products? A systematic review of evidence from low-income and middle-income countries. BMJ Glob Health 2017;2:e000243.

13 Nunan M, Duke T. Effectiveness of pharmacy interventions in improving availability of essential medicines at the primary healthcare level. Trop Med Int Health 2011;16:647-58.

14 Riewpaiboon A, Sooksriwong C, Chaiyakunapruk N, et al. Optimizing national immunization program supply chain management in Thailand: an economic analysis. Public Health 2015;129:899-906.

15 Alabbadi I. Cost impact of purchasing pharmaceuticals jointly in the public health sector in Jordan. Jordan J Pharmaceut Sci 2011;4:97-104.

16 Danzon PM, Mulcahy AW, Towse AK. Pharmaceutical pricing in emerging markets: effects of income, competition, and procurement. Health Econ 2015;24:238-52.

17 Milovanovic DR, Pavlovic R, Folic M, et al. Public drug procurement: the lessons from a drug tender in a teaching hospital of a transition country. Eur J Clin Pharmacol 2004;60:149-53.

18 Arney L, Yadav P. Improving procurement practices in developing country health programs, 2014. Available: https://wdi.umich.edu/ wp-content/uploads/WDI- -Improving-Procurement-Practice-inDeveloping-Country-Health-Programs_Final-Report_2.pdf [Accessed 25 Nov 2019].

19 Johns B, Baltussen R, Hutubessy R. Programme costs in the economic evaluation of health interventions. Cost Eff Resour Alloc 2003;1:1

20 Dang A, Likhar N, Alok U. Importance of economic evaluation in health care: an Indian perspective. Value Health Reg Issues 2016:9:78-83

21 Wiedenmayer K, Mbwasi R, Mfuko W, et al. Jazia prime vendor system- a public-private partnership to improve medicine availability in Tanzania: from pilot to scale. J Pharm Policy Pract 2019:12:4.

22 Wiedenmayer K. Complementing the medicines supply gap with a regional prime vendor system - a Public-Private-Partnership; improved availability of supplementary medicines and medical supplies through Dodoma regional prime vendor. Dodoma, Tanzania, 2017.

23 Kiologwe J. Establishment of a prime vendor system to complement public sector supply as a public-private partnership in Tanzania: global health supply chains Summit, 2016. Dar es Salaam, Tanzania, 2016.

24 HPSS. Complementing the medicines supply gap with a regional prime vendor system in Dodoma region. Dodoma, 2014.

25 Yale. The medical stores department: an innovative public-private partnership: medical supply solutions in Tanzania, 2011. Available: http://nexus.som.yale.edu/ph-tanzania/?q=node/111 [Accessed 8 Nov 2016]

26 HPSS. News and Announcements Launch of a new regional prime vendor system for supplementary medicines and supplies in dodoma region, 2011. Available: http://www.hpss.or.tz/index.php/ 66-news/318-launch-of-a-new-regional-prime-vendor-systemfor-supplementary-medicines-and-supplies-in-dodoma-region [Accessed 30 Nov 2016].

27 PO-RALG. The United Republic of Tanzania President's Office Regional Administration and Local Government; Monitoring and
Evaluation Framework PVCO Staff Handbook; Ver -2, Dodoma, Tanzania, 2016

28 Xu X, Grossetta Nardini HK, Ruger JP. Micro-costing studies in the health and medical literature: protocol for a systematic review. Syst Rev 2014;3:47.

29 Cunnama L, Sinanovic E, Ramma L, et al. Using top-down and bottom-up costing approaches in LMICs: the case for using both to assess the incremental costs of new technologies at scale. Health Econ 2016;25 Suppl 1:53-66.

30 Vassall A, Sweeney S, Kahn J. Reference case for estimating the costs of global health services and interventions. Global Health Cost Consortium, 2017. https://researchonline.Ishtm.ac.uk/id/eprint/ 4653001

31 Hendriks ME, Kundu P, Boers AC, et al. Step-By-Step guideline for disease-specific costing studies in low- and middleincome countries: a mixed methodology. Glob Health Action 2014;7:23573.

32 Flessa S, Moeller M, Ensor T, et al. Basing care reforms on evidence: the Kenya health sector costing model. BMC Health Serv Res 2011:11:128

33 WHO. Making choices in health: who guide to cost-effectiveness analysis. World Health Organization, Geneva, 2003.

34 Evans CJ, Crawford B. Data collection methods in prospective economic evaluations: how accurate are the results? Value Health 2000;3:277-86.

35 Drummond M, Sculpher M, Torrance G. Methods for the economic evaluation of health care programmes, 1987.

36 SalaryExplorer. Health and medical average salaries in Tanzania 2019. how much money does a person working in health and medical make in Tanzania? 2019. Available: http://www. salaryexplorer.com/salary-survey.php?loc=214\&loctype=1\&job=2\& jobtype=1\#disabled [Accessed 18 Oct 2019]

37 Frick KD. Microcosting quantity data collection methods. Med Care 2009;47:S76-81.

38 Drummond MF, Sculpher M, Claxton K. Methods for the economic evaluation of health care programmes. 2nd edn. Oxford: Oxford Medical Publications, 2015.

39 Briggs AH, Gray AM. Handling uncertainty in economic evaluations of healthcare interventions. BMJ 1999;319:635-8.

40 Turner HC, Lauer JA, Tran BX, et al. Adjusting for inflation and currency changes within health economic studies. Value Health 2019;22:1026-32.

41 Kumaranayake $\mathrm{L}$. The real and the nominal? making Inflationary adjustments to cost and other economic data. Health Policy Plan 2000;15:230-4.

42 BoT. Bank of Tanzania reports 2018, Dar ES Salaam, Tanzania. Available: https://www.bot.go.tz/Publications [Accessed 15 Oc 2019].

43 Hamel DJ, Sankalé J-L, Samuels JO, et al. Building laboratory capacity to support HIV care in Nigeria: Harvard/APIN PEPFAR, 2004-2012. Afr J Lab Med 2015;4:190.

44 Goodman CA, Mutemi WM, Baya EK, et al. The cost-effectiveness of improving malaria home management: shopkeeper training in rural Kenya. Health Policy Plan 2006;21:275-88.

45 Mwencha M, Rosen JE, Spisak C, et al. Upgrading supply chain management systems to improve availability of medicines in Tanzania: evaluation of performance and cost effects. Glob Health Sci Pract 2017:5:399-411.

46 Joy K, Stewart E. Malawi: business case for an electronic logistics management information system. Arlington, Va.: USAID deliver project, task order 4 and task order 7, 2013.

47 Fiedler JL. The Nepal national vitamin A program: prototype to emulate or donor enclave? Health Policy Plan 2000;15:145-56.

48 Kafle KK, Gartoulla RP, Pradhan YM, et al. Drug retailer training: experiences from Nepal. Soc Sci Med 1992;35:1015-25.

49 Chaudhury RR, Parameswar R, Gupta U, et al. Quality medicines for the poor: experience of the Delhi programme on rational use of drugs. Health Policy Plan 2005;20:124-36.

50 NBS. National Bureau of statistics (2012) population distribution of Tanzania regions by district, ward and Village/Mtaa, 2012.

51 BOT. Bank of Tanzania: annual report 2018/19, Dar ES Salaam: Tanzania. Available: https://www.bot.go.tz/Publications/Economic AndOperationsAnnualReports/ANNUAL\%20REPORT\%202018-19\% 20SIGNED.pdf [Accessed 28 Jan 2020].

52 Sorensen T, Codjia P, Hoorelbeke P, et al. Integrating nutrition products into health system supply chains: making the case. Field Exchange 51, p142, 2016. Available: https://www.ennonline.net/fex/ 51/integratingnutritionproducts [Accessed 13 Jan 2020].

53 Eby E, Daniel T, Agutu O, et al. Integration of the UNICEF nutrition supply chain: a cost analysis in Kenya. Health Policy Plan 2019;34:188-96. 